\title{
Familias pobres, niñas y benefactoras. Estrategias y expectativas en el centro y sureste de la provincia de Buenos Aires a principios del siglo $\mathrm{xx}$
}

\author{
Yolanda de Paz Trueba \\ CONICET /IEHS-IGECHS/ UNCPBA
}

\section{Resumen}

Este artículo propone un recorrido a través de una serie de casos en los cuales diversos actores sociales de comunidades del centro y sureste de la provincia de Buenos Aires, se acercaron a los asilos de huérfanas locales solicitando un lugar en ellos para niñas que atravesaban por situaciones de orfandad y abandono.

El objetivo de este trabajo es analizar los motivos que generaron estas peticiones, pero sobre todo la forma en que éstas fueron entabladas. Se busca reflexionar en torno a las estrategias que desarrollaron las familias trabajadoras a la hora de encarar la crianza de su prole.

\section{Palabras claves}

Familias trabajadoras, niñas, pobreza, estrategias, asilos

\begin{abstract}
This article proposes to run over a series of cases in which a variety of community partners in the Centre and South-East of Province Buenos Aires, went to local girl orphanages asking shelter for girls who were experiencing orphan or abandonment conditions.

The objective of this research work is not only to analyze the reasons for this kind of requests, but especially the way they were initiated. The aim is to think about the strategies developed by working families when facing the upbringing of their progeny.
\end{abstract}

\section{Keywords}

Working Families, girls, poverty, strategies, orphanage 


\section{Familias pobres, niñas y benefactoras}

En 1915, Felipe Demarco llegó al asilo de niñas de Tandil solicitando un lugar para alojar a una hija suya de 11 años de edad, manifestando que "(...) en su carácter de trabajador y careciendo de medios, le impiden atenderla y cuidar de su educación". Razones que, como dejaron asentado las Damas de Caridad en sus actas de sesiones, le abrieron las puertas de la institución. ${ }^{1}$

Se trataba del Asilo para niñas huérfanas que la Sociedad Damas de Caridad del Sagrado Corazón de Jesús, congregación femenina laica de fuerte vinculación con la Iglesia católica local, había inaugurado en el pueblo en 1897. También en la vecina localidad de Azul, una comisión del mismo nombre y características similares, sostenía un internado para niñas desde 1896. En ambos pueblos del centro y sureste de la provincia de Buenos Aires (espacio abordado en el análisis propuesto en las páginas que siguen), estas comisiones se habían organizado en los tramos finales del siglo XIX con la intención de atenuar las situaciones de orfandad y abandono que afectaban a ciertos sectores de la infancia local, especialmente niñas.

Antes de llegar al asilo, probablemente las familias trabajadoras recurrían a una red propia de parientes, amigos, vecinos o allegados. Esta sería la primera opción para quienes no podían mantener a sus hijas a su lado. Pero cuando ese entramado relacional propio (que podría suplir a la familia en casos de necesidad extrema), mostraba su debilidad, las instituciones asilares como las aludidas aparecían como una alternativa a la hora de criar y educar a los miembros más pequeños de las familias pobres. ${ }^{2}$ Además, una exposición de sus motivos en términos que pudieran ser atendibles por parte de quienes se presentaban como aquellas que tenían en sus manos la solución al problema, era un requisito compartido por quienes de un modo u otro acudieron a ellas. En el pedido que Felipe Demarco realizó, utilizó un argumento acorde con las expectativas de las Damas de Caridad. En tanto se presentó como trabajador, no sólo les brindó unas motivaciones para no poder tener a su lado a la niña, sino que también él mismo se mostró como digno de ser ayudado.

Las causas que llevaron a este hombre a solicitar asistencia a las señoras de la beneficencia local, pero sobre todo el modo en que justificó su petición (aludiendo a su calidad de trabajador), invitan a pensar en las estrategias de las familias trabajadoras a la hora de encarar la crianza de su prole, que incluía no sólo proveer de ropa, comida y techo sino también la asistencia a la escuela, todo lo cual implicaba dinero y tiempo. ${ }^{3}$ En un marco de crecimiento poblacional, desarrollo

\footnotetext{
${ }^{1}$ Archivo Sagrado Corazón de Jesús de Tandil (ASCJT), Actas, 22-3-1915.

2 El papel desempeñado por las redes parentales y las instituciones de beneficencia así como las estrategias de las familias trabajadoras a la hora de encarar la crianza de los hijos y la adaptación a nuevas condiciones laborales, ha sido desarrollado por los historiadores de la familia. Entre otros ver Martine Segalen. Antropología histórica de la familia. Madrid, Taurus, 1992 y Tamara Hareven. "Historia de la familia y la complejidad del cambio social". Boletín de la Asociación de Demografía Histórica; Núm. XIII, Vol. I, 1996; pp. 99-149.

3 Para los hijos de las familias pobres, la asistencia a la escuela le restaba tiempo al trabajo (muchas veces familiar) que realizaban desde muy pequeños. Esta necesidad de contar con su colaboración
} 
económico y complejización social por los que atravesaron a principios del siglo XX Azul y Tandil, no fueron pocos aquellos que debieron recurrir a las Damas de Caridad en busca de ayuda. Pero al entablar tales demandas partiendo de una reelaboración de las interpretaciones sobre las funciones de la beneficencia proyectadas por autoridades y miembros de la elite devenidos en benefactores, esos actores sociales entendían que su reclamo no sólo se basaba en una necesidad, sino que además era justo.

La modernización había llegado a ambas localidades desde las décadas finales del siglo XIX de la mano del alumbrado público, el telégrafo, el ferrocarril y la instalación de sucursales de los Bancos de la Provincia de Buenos Aires, Banco Hipotecario Nacional y Banco de la Nación. Los negocios y las incipientes industrias no quedaron al margen de las modificaciones: hoteles, fondas, almacenes, molinos, fábrica de cerveza, de queso, de jabón, grasa, aceites, fundiciones, herrerías, fábricas de carruajes y talleres de construcción de toda clase, dieron vida a la actividad económica local que abarcó no sólo a la zona urbana, sino también a la campaña, y que se acrecentó a medida que avanzaron los primeros años de la nueva centuria.

Además, el progreso edilicio que se manifestaba en los edificios públicos y en las sólidas construcciones particulares de las que eran testigos las calles pavimentadas surcadas a diario por un buen número de carruajes de alquiler, daban la imagen de pueblos pujantes del centro y sureste bonaerense que en los tramos finales del siglo alcanzaron su estatus de ciudad. ${ }^{4}$

Esas mismas calles y espacios públicos eran transitados cotidianamente por niños y niñas, despertando las preocupaciones de los sectores que fundaron instituciones destinadas a dar cobijo a la situación de orfandad y abandono que involucraba a niñas que, como la hija de Felipe Demarco, encontraría en estas techo y educación.

En este trabajo pretendemos a través del análisis de las solicitudes de internación que diferentes sectores de las comunidades involucradas entablaron a lo largo de los años, reconstruir los posibles significados sociales que estas instituciones tuvieron para estos. Buscamos asimismo tomar cierta distancia con una mirada que ve en ellas solo instancias de control social y disciplinamiento. ${ }^{5} \mathrm{Si}$

para la economía familiar así como la imposibilidad de vestirlos y calzarlos adecuadamente era esgrimido por los mismos padres al momento de justificar la ausencia de sus hijos de las aulas de las escuelas públicas en los pueblos estudiados. Durante el periodo abordado, otras instituciones del sector privado surgieron con el objetivo de proveer a estos niños con ropa y calzado para mitigar la inasistencia escolar. Al respecto nos hemos referido en de Paz Trueba, Yolanda "La educación de la infancia: prácticas del sector privado en el centro y sur bonaerenses a fines del siglo XIX y comienzos del XX", en María Ana Manzione, Lucía Lionetti y Cecilia Di Marco (Comps.), Educación, Infancias(s) y Juventud(es) en diálogo. Saberes, representaciones y prácticas sociales, Bs. As., Ed. La Colmena, pp. 155 a 177.

${ }^{4}$ Azul lo hizo en 1894 y Tandil en 1895.

${ }^{5} \mathrm{Si}$ bien en el marco temporal estudiado existió una profusión discursiva en torno a la necesidad de introducir elementos normalizadores y disciplinadores (especialmente sobre los sectores populares que parecían poner en peligro el orden social) los desarrollos historiográficos de las 


\section{Familias pobres, niñas y benefactoras}

bien como trasfondo de la fundación y sostenimiento de los asilos, había una preocupación social en torno a la infancia errante y vagabunda en tanto entrañaban un peligro para el orden social y político, no podemos obviar el hecho de que esas mismas instituciones se consolidaron a partir de un complejo entramado relacional del que formaron parte importante los sujetos sociales que hicieron uso de ellas, delineando con sus demandas y sus sentidos propios, los contornos de las mismas.

Si bien la información sobre Felipe Demarco y su hija (así como la de las demás niñas y familias que se presentan en las páginas que siguen), se reduce a fragmentos, un abordaje a contrapelo de las actas de las instituciones asilares a las que recurrieron pidiendo ayuda entre 1896 y 1920, puede ayudar en el rastreo de sus huellas.

Para ello, en una primera instancia, nos acercamos a los pedidos de ingreso de niñas que diversos actores sociales de las comunidades analizadas hicieron a las comisiones de beneficencia que sostenían los asilos locales, poniendo de manifiesto en ellos no solo las necesidades concretas de las niñas a raíz de sus situaciones de orfandad y abandono, sino también cómo formaban parte de redes de parientes y allegados por las que circularon antes de llegar a las instituciones analizadas. En un segundo momento, nos detenemos en las solicitudes hechas por los padres y madres de las niñas, a través de las que buscamos poner el acento en las estrategias desplegadas a la hora de bregar por obtener un lugar en los asilos, así como sus maneras de exponer sus necesidades pero también sus derechos. En este sentido en un último apartado, buscamos dar cuenta del modo en que esas estrategias parecían acentuarse cuando los pedidos llegaban desde localidades circundantes. Ante la falta de recursos, quienes buscaron un lugar para alojar a las niñas no sólo hicieron hincapié en sus necesidades, sino que conocedores de las limitaciones de los asilos para responder a sus demandas, buscaron articular y movilizar en beneficio propio sus relaciones personales con benefactores de las instituciones o con miembros de las comisiones que los administraban.

En síntesis, proponemos un recorrido a través de las huellas que estos actores dejaron en las fuentes analizadas, haciendo hincapié en las estrategias

últimas décadas han mostrado las precauciones que debemos tener a la hora de pensar en la unanimidad de esos dispositivos disciplinadores así como en el éxito de los mismos.

Tributarios de la línea de trabajos que buscaba recuperar las acciones de los subalternos, estos estudios han mostrado como los actores sociales objetos de control, podían no compartir las normas a las que se pretendía ajustarlos, al tiempo que ponían de manifiesto resistencias y negociaciones en sus prácticas cotidianas. A partir de lo que las fuentes aquí estudiadas revelan, buscamos dar cuenta de que no es posible pensar el control como una instancia de dominación ejercida desde arriba hacia abajo. Justamente en este trabajo se busca ir más allá y recuperar las agencias comunitarias, sus vivencias y estrategias, a la hora de recurrir en busca de ayuda a instituciones asilares que, tal como aquellas interpretaciones más tradicionales habrían pensado, estaban diseñadas para moralizar y disciplinar los comportamientos de los niños de los sectores populares. 
desplegadas a la hora de resolver, aunque fuera de modo transitorio, sus necesidades.

\section{Los actores sociales ante las posibilidades que la beneficencia brindaba}

En 1899, Teresa Montenegro llegó al asilo de huérfanas de Tandil, cuando la mujer que se encargaba de su crianza, Socorro Ludueña, lo solicitó por encontrarse enferma. La mujer hizo el pedido por un período de tiempo determinado, “(...) solo mientras duraba la enfermedad que la tenía postrada". Sin embargo, y contra sus propias suposiciones, Socorro falleció y la niña quedó bajo el amparo de las Damas de Caridad por ser “(...) completamente huérfana”. Así lo informó la presidenta de la comisión al resto de las mujeres que la componían tres años más tarde de haber tenido lugar el ingreso, cuando se encontraron frente a la necesidad de decidir el destino de la pequeña Teresa “(...) por cuanto las Hermanas la tienen siempre separada de las otras huérfanas a causa de su mal carácter". ${ }^{6}$ La mención de problemas de conducta manifestados por las internas, era recurrente en las actas de reuniones de las comisiones directivas de los asilos. Si bien tales problemas no eran descritos detalladamente, se trataría de resistencias que exteriorizaban las niñas ante las reglas de funcionamiento interno de las instituciones, impuestas por las hermanas de las congregaciones que se encargaron de su administración cotidiana. ${ }^{7}$ En tales casos, si los llamados de atención no daban la respuesta esperada, los miembros de las comisiones podían decidir colocar a las chicas en cuestión en casas de familias decentes de los pueblos analizados. ${ }^{8}$ Si bien nada nos exime de pensar que durante su estadía con familias locales no debían colaborar con los servicios domésticos de la casa seleccionada, esas tareas eran vistas en estos casos como una forma de socialización para el futuro antes que como un trabajo en sí mismo. Dado que por este medio se podían aprehender comportamientos y habilidades útiles para el futuro, las señoras de la beneficencia local encontraron que esta era la solución al problema que por entonces representaba para ellas Teresa Montenegro. ${ }^{9}$ Con esta medida, creían que podían

\footnotetext{
${ }^{6}$ ASCJT, Actas, 24-3-1901.

${ }^{7}$ En Tandil se destacó el accionar de la Congregación Hijas de la Misericordia y en Azul las hermanas de la Congregación de las Hijas del Divino Salvador quienes estuvieron al frente durante los primeros diez años de vida del asilo. Desde 1906, se hizo cargo de sus tareas la Congregación de la Inmaculada Concepción.

${ }^{8}$ La figura de la colocación implicaba encontrar un lugar para las niñas y jóvenes a su cago, en casas de familias en las que se suponía debían ser cuidadas y también se les debían transmitir pautas morales y de comportamiento adecuadas. Si dicha colocación representaba en algunos casos una salida laboral para las asiladas tras el abandono de la institución, en algunos casos y desde la visión de las damas, del cura párroco que oficiaba como director de la asociación y de la superiora, aparecía también como un camino de corrección para los problemas de conducta, como el paso previo a una solución más radical: la de trasladar a las niñas a una institución correccional fuera del pueblo, cuando aún tenían edad para permanecer en el asilo.

${ }^{9}$ A medida que transcurrían los primeros años del siglo XX, del análisis de las discusiones de las comisiones ha sido posible inferir la importancia que las benefactoras locales le dieron no solo a su trabajo asistencial sobre las niñas sino también a su tarea de cara al futuro de estas como madres y trabajadoras A través de este análisis nos hemos adentrado en el sentido de la responsabilidad
} 
por un lado preservar al resto de las asiladas del comportamiento inadecuado de esta huérfana. Por otra parte, colaborarían con la enmienda de la misma por cuanto, como ha señalado María Marta Aversa, el trabajo de los menores era vislumbrado como una herramienta de regeneración de “(...) hábitos y costumbres perniciosas $(\ldots) " .{ }^{\prime 10}$

A principios del silgo XX, las niñas alojadas en los asilos de huérfanas de las Damas de Caridad de Azul y Tandil, llegaron allí por diversas situaciones de soledad y abandono, que podía darse como consecuencia del fallecimiento de los padres, tras el cual las pequeñas quedaban al cuidado de terceros (no siempre familiares directos) que al poco tiempo podían desentenderse de ellas, o verse en la obligación de recurrir a instituciones como las estudiadas. ${ }^{11}$

Así, no era infrecuente que las niñas ingresaran a estos asilos a partir de solicitudes hechas por parientes y allegados que, como Socorro Ludueña, tenían pequeñas a su cargo tras la muerte de alguno de los progenitores o de ambos. En tales casos, lo habitual era que las redes amicales y parentales de contención se activaran brindando soluciones en coyunturas de extrema necesidad antes que las

social que tenían estas mujeres, tal como hemos puntualizado en algunos trabajos previos: Yolanda de Paz Trueba. "Niñas, monjas y damas de beneficencia en un asilo de huérfanas del sur bonaerense. Tandil, 1897-1919". 3ras Jornadas "Estudios sobre infancia. Vida cotidiana, saberes y políticas públicas en Argentina y Latinoamérica (1880-2010)", UNGS, 1 y 2 de noviembre de 2012 y "Política social católica: una forma de intervención pública en el ámbito privado de la familia. La campaña centro y sur bonaerense a principios del siglo XX". Jornadas Arreglos familiares, género y sexualidad, CiSoC, FCH UNICEN, Tandil, 12 y 13 de junio de 2014.

10 María Marta Aversa, "Colocaciones y destinos laborales en niños y jóvenes asilados en la ciudad de Buenos Aires (1880-1900)", en Lucía Lionetti y Daniel Míguez (Comps.). Las Infancias en la Historia Argentina. Intersecciones entre Prácticas, Discursos e Instituciones (1890-1960). Prohistoria, Buenos Aires, 2010, pp.35-52, p. 43. Estas cuestiones forman parte de una agenda mayor de preocupación en América Latina. Entre muchos autores referenciamos a Susana Sosenky, quien ha analizado cómo desde el siglo XIX se extendió la valoración del trabajo como herramienta de regeneración para menores que habían delinquido, siendo en el caso de las niñas, el servicio domestico uno de los destinos preferenciales. Ver Susana Sosensky, "Un remedio contra la delincuencia: el trabajo infantil en las instituciones de encierro de la ciudad de México durante la posrevolución”, en Asclepio. Revista de Historia de la Medicina y de la Ciencia, Vol. LX n², 2008, pp. 95-118 y de la misma autora Niños en acción. El trabajo infantil en la ciudad de México 1920-1934, México, El Colegio de México, 2010.

11 Si bien en los casos presentados aquí aludimos a niñas que experimentaron la soledad o el abandono a partir de la muerte de los padres, también podían darse situaciones similares a raíz de la partida de los progenitores a Europa, de donde habían llegado. Estos casos solían ser frecuentes en los pueblos estudiados, ya que desde fines del siglo se experimentaba en la zona un marcado crecimiento poblacional que en gran medida se debía al arribo de población extranjera o de migrantes de otros lugares del país, en busca de oportunidades laborales. De acuerdo al Censo Nacional de Población de 1895, Azul tenía un total de habitantes entre población urbana y rural de 23.115 personas, y Tandil 14.982. Para 1914, las cifras habían aumentado notablemente, contándose los habitantes de Azul en 32.103 y los de Tandil en 34.061. Además, se observa una coincidencia con el resto de la provincia en cuanto al aumento de población urbana. Sin embargo, encontramos matices en cada uno de ellos: mientras que en Azul fue marcado el crecimiento en la urbanización y una leve disminución de la población rural (pasando la población urbana de 9.494 a 19.602 y de 13.621 bajaron a 12.501 los residentes en el campo), en Tandil, el crecimiento urbano fue importante pero el rural lo acompañó en forma proporcional (de 7.088 personas a 15.774 en 1895 y de 7.894 a 18.277en 1914). 
organizaciones de la beneficencia local. La economía moral ${ }^{12}$ se ponía en funcionamiento rápidamente para resolver situaciones de emergencia. Pero cuando estas redes se debilitaban por alguna contingencia en particular (como fue la enfermedad seguida de muerte de Socorro), o cuando simplemente no había parientes ni vecinos que pudieran hacerse cargo de los miembros más pequeños de las familias pobres, entonces las instituciones asilares solían ser la única solución para muchas niñas de los pueblos estudiados. Así lo entendió María de Suarez quien solicitó en Azul lugar para una niña a la que criaba y era "(...) huérfana de padre y madre (...) comprometiéndose a darle todo lo que necesitara". ${ }^{13}$ Por su parte, Juana y María Usabiaga de 9 y 7 años respectivamente, además de ser huérfanas, carecían de tutor, lo que llevó a las damas de la comisión de Tandil a solicitar al defensor de menores local el nombramiento de uno. ${ }^{14}$ Mientras tanto, los muros del asilo representaban para estas hermanas la diferencia entre cierta protección y disponer de un techo, comida y educación, o continuar su circulación, tal vez por separado. ${ }^{15}$

La percepción de estas instituciones como lugar de cobijo ante la ausencia de padres, parecía ser compartido por una multiplicidad de actores sociales que recurrieron a una y otra institución a lo largo de estos años solicitando un espacio para ellas, como lo hicieron Berta de Esmerotte y Juan Saraví, quienes entendieron que el asilo era el mejor lugar para resguardar de su desamparo a dos huérfanas,

\footnotetext{
12 Noción acuñada originalmente por E.P. Thompson en 1979 para explicar el comportamiento popular en los motines de subsistencias del siglo XVIII. Tal como aquí lo usamos, estamos refiriendo a la conducta sostenida por diversos actores sociales de las comunidades estudiadas, guiados por sentimientos de mutua cooperación. E.P. Thompson. Costumbres en común. Barcelona, Crítica, 1995.

${ }^{13}$ Archivo Sagrado Corazón de Jesús de Azul (ASCJA), Actas, 13-3-1898.

${ }^{14}$ ASCJT, Actas, 2-4-1905. Hasta entrado el siglo XX los contemporáneos no pensaron lo social en términos de derechos sino más bien en la necesidad de regular ciertos comportamientos de los sectores populares (incluidos los niños), ya que creían que ponían en peligro el orden social. En este contexto, existía un marco legal que buscaba articular modos de protección de aquellos sectores que, como los niños de las familias pobres eran percibidos en estado de vulnerabilidad. Los defensores de menores locales debían desempeñar un conjunto amplio de tareas relacionadas con la colocación, el bienestar, educación y cuidado de los bienes de los niños huérfanos o abandonados de cada localidad. Por lo tanto, es dable suponer que cuando las señoras de la beneficencia recurrieron al defensor local lo hicieron a partir de su propia noción acerca de los derechos de las hermanas Usabiaga, más allá de la protección efectiva que pudiera brindarles el defensor o un eventual tutor.

${ }^{15} \mathrm{Al}$ menos Juana permaneció muchos años en el asilo, donde la enfermedad que la aquejaba determinó su traslado al Hospital Municipal, en el que finalmente falleció. ASCJT, Actas, 22-3-1915. Por circulación entendemos el hecho de que los niños no se criaran con sus familias biológicas, sino que parte de su infancia podía transcurrir pasando por varias casas diferentes. Si el defensor hubiera decidido que las hermanas Usabiaga no quedaran a cargo de las Damas de Caridad y en cambio hubiera encontrado una colocación en casa de una familia del pueblo, como solía hacer en la mayoría de los casos de niñas que estaban bajo su responsabilidad, lo habitual era que estas chicas vivieran a lo largo de algunos años con diferentes familias, o bien porque los guardadores pedían al defensor "devolverlas" por algún problema de conducta que observaban en ellas, o a raíz de las fugas protagonizadas por las niñas y jóvenes de las casas de sus tutores, aludiendo malos tratos por parte de aquéllos que debían resguardarlas.
} 


\section{Familias pobres, niñas y benefactoras}

"niñas de Altamiranda",16 o como sucedió también con Carlos Vitoy quien pidió internar una "(...) huérfana de madre y padre" que tenía a su cargo. ${ }^{17}$

En los casos mencionados, las demandas se efectuaron aludiendo a la imposibilidad de continuar cuidando de las pequeñas que, ante la completa orfandad, quedaban totalmente desamparadas. Si bien estos pedidos de ingresos no fueron cuestionados por los miembros de las comisiones cuando no se interponía un problema de escasez de espacio o la edad de las niñas no era inferior a los 5 años, en otras oportunidades pesó la condición de quienes hicieron tal solicitud, como en el caso de "(...) las niñas de Otero, huérfanas de padre y madre (...)" por quienes "rogaba" un lugar en el asilo Antonio Santamarina. Su cualidad de importante benefactor de la institución, era la carta tácita que le permitió hacer este pedido. ${ }^{18} \mathrm{~A}$ veces esas redes alcanzaban a los miembros de las asociaciones, como la señora Marta de Cornille, pro tesorera de la comisión de Azul, quien solicitó un lugar en el asilo de ese pueblo para una pequeña de 12 años. Así, si la total orfandad de la niña no hubiera sido motivo suficiente para su admisión, su desempeño en la asociación hizo que el ingreso no fuera puesto en tela de jucio. ${ }^{19}$ No era infrecuente la recurrencia a estas mujeres en forma personal para movilizar en beneficio propio su situación en las instituciones de beneficencia, buscando que estas interpelaran al resto de las señoras de las comisiones en su favor.

\section{Madres y padres ante las benefactoras}

La debilidad (o fortaleza) de las redes amicales no solo se hacía evidente cuando las niñas carecían de padres y eran estas las que servían de contención. El análisis de las fuentes de los asilos estudiados pone de manifiesto que no fueron pocas las oportunidades en que los mismos padres y madres recurrieron al asilo a falta de aquellas. En tal sentido, dado que los asilos recogieron tanto a niñas huérfanas como a otras que no lo eran, muchas llegaron a ellos tras el pedido que su madre o padre hicieron para dejarlas al cuidado de las monjas que regían el devenir cotidiano de las instituciones. En tales casos, jugó a favor de los solicitantes (mucho más que en el caso de aquellas que eran realmente huérfanas), la manera en que supieron exponer sus necesidades ante quienes se presentaron como las dadoras de soluciones a sus desesperadas situaciones que, las más de las veces, tenían que ver con la pobreza y la imperiosa necesidad de trabajar, lo que en algunos casos debían poder además documentarlo. La presentación del certificado de pobre de solemnidad era el pasaporte para el ingreso que un padre debió presentar para que su hija fuera aceptada en Tandil en $1904 . .^{20}$ En otro caso, si

\footnotetext{
16 ASCJT, Actas, 27-4-1914.

17 ASCJT, Actas, 28-8-1914.

18 ASCJT, Actas, 4-6-1914.

${ }^{19}$ ASCJA, Actas, 17-2-1898.

20 Se trataba de una certificación que otorgaban las autoridades a aquéllos pobres que por ser trabajadores y no observar conductas inapropiadas, se consideraban merecedores de las atenciones
} 


\section{Yolanda de Paz Trueba}

bien el Sr. Fregosini pidió que le fueran recibidas tres niñas, lo cual implicaba un esfuerzo para las capacidades del asilo siempre puestas al límite por las demandas crecientes, la exposición de su extrema necesidad fue lo que hizo que su pedido se resolviera favorablemente. ${ }^{21}$

Si la enfermedad podía definir la decisión de una madre de recurrir a las damas, también podía inclinar a su favor la balanza al momento en que éstas debían tomar una decisión. Esas fueron las razones que argumentó una mujer de Azul para dejar en el Sagrado Corazón a una hija de 8 años, a la que según decía, en esas circunstancias"(...) no podía atenderla”, o el caso de otra mujer de la misma localidad que años más tarde, puso en carácter de huérfana una hija de 9 años. ${ }^{22}$

En estas decisiones de las madres, jugaron varios factores además de los que resultaron evidentes a partir de su propia exposición de motivos. De acuerdo con lo que sostiene Rachel Fuchs, culturalmente las tareas domésticas entre las cuales se contaban el cuidado de los hijos, eran entendidas como propias de las mujeres, y cuando estas no podían atender a sus hijos por la necesidad de trabajar, los hombres no asumían ese papel, y es aquí cuando se releva la importancia de la presencia de otros miembros femeninos de la familia o la comunidad que pudiera ayudarlas. ${ }^{23}$ Sin embargo, los casos antes comentados demuestran que, para las familias trabajadoras no siempre la existencia de miembros femeninos garantizó la crianza de la descendencia en el entorno familiar.

En ocasiones eran los padres, como el de las niñas Carmen e Isabel Siciliana o como el de Emma y Dolores Capurro quienes solicitaron la internación de sus hijas. ${ }^{24}$ La viudez en algunos casos y la necesidad de trabajar siempre, definían esas decisiones. Para los hombres, el asilo representaba una opción ante la falta de otras que combinaba contención con transmisión de conocimientos, percepción compartida por los mismos actores que recurrieron a ellos en busca de ayuda, tal como lo expuso el ya mencionado Felipe Demarco.

Además, desde fines del siglo XIX la alta movilidad en busca de mejores posibilidades de trabajo, afectó a lugares como los estudiados, centros productivos de la provincia que en el momento estudiado atravesaron por un proceso de expansión tanto de la agricultura como de la ganadería además del desarrollo del comercio y las incipientes industrias, cuya influencia abarcó no solo al área urbana sino a la zona rural circundante, demandando constantemente mano de obra estacional junto a la estable. Por lo tanto, si a la ausencia de la figura materna sumamos que un padre viudo podía ser nuevo en la comunidad, la carencia de vínculos que le permitieran mantener a sus hijas consigo mientras trabajaba, era

brindadas por la beneficencia. En el caso de los asilos mencionados, una recomendación por parte del párroco que oficiaba como director de las comisiones, tenía una validez similar, y era lo que en muchas ocasiones presentaron quienes recurrieron a las Damas de Caridad.

${ }^{21}$ ASCJT, Actas, 12-2-1909.

22 ASCJA, Actas, 3-7-1898; ASCJA, Actas, 22-3-1900.

23 Rachel Fuchs. "Beneficencia y bienestar"; en David Kertzer y Mario Barbagli (Comps.). La vida familiar desde la Revolución Francesa hasta la primera guerra mundial (1789-1913). Barcelona, Paidos, 2003, pp.243-296, p. 244.

${ }^{24}$ ASCJA, Actas, 6-9-1897 y ASCJA, Actas, 5-11-1899. 


\section{Familias pobres, niñas y benefactoras}

motivo suficiente para recurrir al asilo. Tan solo 5 años tenía una niña que quería ser puesta en el asilo de Azul por el padre quien como dejó expuesto ante las Damas de Caridad "(...) se comprometía a darle la cama con todo lo necesario y pagaría \$5 mensuales". ${ }^{25}$ Probablemente no fue la pobreza lo que lo llevó a reclamar un lugar para su hija, sino la imposibilidad de mantenerla a su lado. ${ }^{26}$

Cuando más pequeñas eran las niñas, más dificultoso se tornaba tanto cuidarlas por sí mismos como conseguir quien lo hiciera por ellos, y la beneficencia se presentó entonces como la única salida que a veces, a diferencia de lo que las Damas de Caridad pretendían, era pensada por quienes hacían uso de ella, como circunstancial. Así fue el caso de Domingo Romeo, cuyas hijas fueron aceptadas en el asilo de Azul en virtud de su situación de indigencia, como él bien se ocupó de exponer en unos términos acordes con lo que las señoras de la elite local entendieron como legítimo, reelaborando en sus propios términos los motivos por los cuales creía que su pedido era justo. ${ }^{27}$ Como sostiene Valeria Pita, "(...) frente a la posibilidad de tener al menos un alivio temporario, quienes se presentaron no dudaron en presentar sus vidas en los términos en que otras mujeres con mucho mas poder y dinero podían llegar a comprenderlas". ${ }^{28}$

Pero si bien el acuerdo firmado entre Domingo Romeo y las Damas de Caridad estipulaba que dejaría a las pequeñas Ema y Clara allí hasta su mayoría de edad, como era el deseo de ellas en todos los casos a fines de garantizar la formación impartida, no pasó mucho tiempo hasta que entabló un reclamo para que le fueran restituidas sus hijas. Aunque en un primer momento hubo señoras que se opusieron a entregarle a las niñas, lo que generó “(...) un breve cambio de ideas (...)", finalmente aceptaron acceder a su pedido. ${ }^{29}$ ¿Qué llevó a este padre a reclamar a sus hijas? ¿La pobreza extrema que padecía se había atemperado? ¿Había conseguido quien atendiera a las niñas? ¿Se había producido un cambio en su situación laboral que le permitía cuidar de ellas? Cualquiera de estos motivos (o una combinación de ellos) podrían conformar una respuesta. Lo cierto es que la situación de Romeo no fue una excepción y los pedidos de restitución de niñas hechas tanto por padres y sobre todo por madres, fueron múltiples. Tal fue el caso de la madre de las niñas María y Josefa Paniagua, cuyo retiro se acordó tras la solicitud, o Lucía Dell'Aglio, quien pidió en 1903 retirar a su hija del asilo de Azul, como se lo manifestó a la Superiora, por nombrar solo algunos. ${ }^{30}$

\footnotetext{
${ }^{25}$ ASCJA, Actas, 11-11-1898.

26 No debemos sin embargo sobrestimar la capacidad pecuniaria de este hombre, un trabajador pobre que no podía despreocuparse totalmente de su situación económica, ya que se comprometía a pagar una cuota bastante inferior a la estipulada por las señoras, fijada en \$15 mensuales.

27 ASCJA, Actas, 20-11-1899.

28 Valeria Silvina Pita, "De trabajos, demandas y limosnas o los modos de vivir en la ciudad de Buenos Aires. 1852-1870”, comunicación presentada en el Seminario Permanente de Historia Social, Colegio de México el 7 de abril de 2014, D.F. México.

${ }^{29}$ ASCJA, Actas, 20-1-1900.

30 ASCJA, Actas, 22-4-1900; ASCJA, Actas, 9-9-1903. Sobre el particular nos hemos referido en Yolanda de Paz Trueba. "Asilos para huérfanas en el centro y sur bonaerenses. Algunas pistas para repensar la construcción de la gobernabilidad a fines del siglo XIX y principios del XX"; en Lucía
} 
En definitiva esto revela, subrayamos, el carácter transitorio que el asilo asumió para muchos de estos sujetos que recurrieron a él como parte de un conjunto de soluciones que tenían a su alcance.

\section{Necesidades regionales ante instituciones de carácter local}

Los habitantes de localidades de la región como Rauch, Las Flores, Juárez, Vela y Olavarría entre otros, sabían que los asilos de Tandil y Azul representaban para ellos un camino plausible ante la necesidad. Esto puso con frecuencia en ciertos apuros a quienes administraban estas instituciones que no contaban con los medios (económicos y de espacio disponible para recibir nuevas internas) para satisfacer una demanda creciente, razón por la cual no siempre fueron aceptadas las solicitudes provenientes de las localidades circundantes, como sucedió en 1910 con una niña procedente de Olavarría a quien se “(...) le contestó que el número reglamentario se halla completo". ${ }^{31}$ También esta decisión se encontró influenciada por la base local que tenía la organización y sostenimiento de la beneficencia. Era elocuente en este sentido el comentario que en 1901 hizo el párroco Guerrero, director de la asociación de Tandil, quien propuso que solo se recibiera niñas de la localidad, “(...) por haber aquí un buen número de pobres que socorrer". La presidenta le respondió que de otras localidades solo se recibían pensionistas, es decir niñas que pagaban una mensualidad a cambio de su estadía en el asilo. ${ }^{32}$

Sin embargo, años después, siguieron llegando niñas de la zona como María Saciain procedente de Vela, ${ }^{33}$ o la hija de la señora de Morales domiciliada en Juárez, quien aludió a su viudez y los problemas que esta le acarreaba para hacerse cargo de una niñita para la que pidió a las Damas de Caridad de Tandil un lugar para ella en calidad de asilada. ${ }^{34}$

En Azul, las dificultades no eran menores y recibir pequeñas de localidades vecinas no hacía más que agravar su situación de escasez permanente. Pero ante las demandas constantes, decidieron organizarse de modo de reunir fondos de los pueblos que solicitaban su ayuda, pasando nota “(...) a las municipalidades de Las

\footnotetext{
Lionetti y Daniel Míguez (Comps.). Las Infancias en la Historia Argentina...cit., pp.53-69 y en "Intervención pública en el ámbito privado de la familia. La campaña centro y sur bonaerense a fines del siglo XIX y primeras décadas del XX", en IV Jornadas Nacionales e Historia Social, La Falda, Córdoba, 15 al 17 de mayo de 2013. Sobre los conflictos que los pedidos de restitución generaron entre las familias y las Damas de la Sociedad de Beneficencia de la Capital ver Carla Villalta. "La conformación de una matriz interpretativa. La definición jurídica del abandono y la pérdida de la patria potestad"; en Lucía Lionetti y Daniel Miguez (Comps.). Las Infancias en la Historia Argentina..., cit.,pp. 71-93. Un referente sobre las intenciones de las madres de volver por sus hijos dejados en el Hogar del Huérfano de la ciudad de Rosario es el trabajo de Gabriela Dalla Corte y Paola Piacenza A las puertas del Hogar. Madres, niños y damas de caridad en el Hogar del Huérfano de Rosario (1870-1920). Rosario, Prohistoria Ediciones, 2006.

${ }^{31}$ ASCJT, Actas, 19-3-1910.

32 ASCJT, Actas, 6-6-1901.

33 Fue aceptada en 1920, pero no consta en qué condición. ASCJT, Actas, 25-3-1920.

${ }^{34}$ ASCJT, Actas, 29-8-1913.
} 


\section{Familias pobres, niñas y benefactoras}

Flores, Tapalqué, Hinojo y Olavarría para que contribuyan con fondos, teniendo derecho luego a enviar huérfanas". ${ }^{5}$

El funcionamiento de las redes parentales no siempre debe hacernos pensar en personas que pudieran tomar a su cargo la crianza de una niña. A veces, si esas redes no alcanzaban para prestar una atención inmediata, podían ser muy útiles a la hora de conseguir soluciones para quienes, en la soledad de su viudez o pobreza, necesitaron recurrir a terceros para cuidar de su prole. Cuando de pedir ayuda a instituciones ajenas a la comunidad se trataba, estas solían adquirir un matiz importante, como sucedió con Micaela R. de Campos, de Las Flores, quien envió una carta a Tandil diciendo que "(...) se hallaba en un caso de extrema pobreza y viuda y pedía por lo tanto se le tomaran en el asilo cuatro niñas de 14 , 12, 10 y 7 años (...)". Como sostiene Valeria Pita para otro colectivo femenino ${ }^{36}$, el hecho de que Micaela (como antes la señora de Morales), se presentaran ante quienes eran sus posibles benefactoras como carente de una figura masculina que hiciera de sostén, fue probablemente un elemento de peso para que estas señoras resolvieran aceptar el pedido, aunque también se sumó en la evaluación favorable en este último caso, que "(...) la carta venía bien recomendada". ${ }^{37}$ Lo que esta mujer parecía tener bien claro era que además de la nota por medio de la que exponía su situación, era importante procurar “(...) articular redes y movilizar influencias en función de sus postulaciones (...)".38

En cambio, era huérfana de madre la niñita de dos años por quien pidió, una vez más, Antonio Santamarina. Dado que la pequeña no llegaba a la edad reglamentaria para aceptarla (estipulada en cinco años), hicieron una excepción por tratarse según decían de un caso de extrema necesidad, y a cambio de que el padre pagara una mensualidad. ${ }^{39} \mathrm{El}$ hecho de que éste pudiera movilizar a su favor su contacto con Santamarina, pudo haber influido en la decisión, además de la necesidad que argumentaba. De este modo, adquiere significancia la capacidad de los sectores populares para orquestar vínculos con personajes prominentes de la localidad y transformar a éstos en colaboradores en su búsqueda de un lugar en el asilo, lo que terminó siendo entablado en términos de derechos en función de necesidades concretas.

La importancia de esta movilización de recursos relacionales, parece quedar claro en otras circunstancias cuando esas excepciones no fueron hechas. Así sucedió en Tandil con una niña cuyo ingreso fue rechazado por ser menor de 5 años. ${ }^{40}$ También en Azul se respondió negativamente años antes a un padre que manifestó su deseo de internar en el asilo tras la muerte de la madre, a dos hijas

\footnotetext{
35 ASCJA, Actas, 20-11-1899.

36 Pita, Valeria Silvina. "Nos termos de suas benfeitoras: encontros entre trabalhadoras e as senhoras da sociedade de beneficência, Buenos Aires, 1852 - 1870", Mundos do Trabalho, I (2) Florianopolis, 2009, pp.41-64.

37 ASCJT, Actas, 4-6-1910.

38 Pita, Valeria Silvina. "Nos termos de suas benfeitoras... ", cit.

${ }^{39}$ ASCJT, Actas, 28-3-1916.

${ }^{40}$ ASCJT, Actas, 6-4-1916.
} 


\section{Yolanda de Paz Trueba}

suyas de 2 y 5 años, al no tener la edad mínima requerida para el ingreso la más pequeña de las niñas. Sin embargo, este caso presentaba otras aristas como lo dejaron claro las mujeres que integraban la comisión al explicar que la casa donde funcionaba el asilo “(...) es muy reducida (...)" y sobre todo en verano “(...) muy expuesta a una peste y después estas niñas tienen familia que pueden cuidar de ellas y no son criaturas completamente desmamparadas como hay otras para quienes hay que reservar siempre un lugar". ${ }^{4}$ Probablemente la edad era una causa entre otras en este rechazo que obedeció antes al conocimiento de la existencia de otras redes que podían contener a las niñas, además de no contar como en el caso de Tandil, con un benefactor por protector al que no podían negar los pedidos en virtud de los múltiples servicios que este prestaba al Asilo. ${ }^{42}$

\section{Conclusiones}

El recorrido propuesto en las páginas precedentes, pretendió aproximarse a través de fragmentos de vida, a las estrategias desarrolladas por familias pobres de Azul, Tandil y algunas localidades de la zona, a la hora de tomar decisiones sobre la crianza de sus hijas, cuando por diversos motivos, no pudieron hacerlo por sus propios medios y se vieron compelidos a pedir un lugar para ellas en los asilos locales para niñas huérfanas.

En los espacios del interior de la provincia de Buenos Aires abordados en este trabajo, las herramientas disponibles para la atención de las vicisitudes que aquejaban a ciertos sectores de la infancia, fueron las que pusieron a disposición las asociaciones de beneficencia privadas. Esas iniciativas estaban pensadas desde una perspectiva dominante acerca de la infancia deseable.

Sin embargo, cuando estos actores sociales hicieron sus presentaciones a las Damas de Caridad, generaron tales pedidos de ayuda desde su propia idea de familia y de responsabilidad para con su descendencia, creando obligaciones e imponiendo sus propias marcas sobre estas instituciones.

Aunque los sujetos que han dejado sus huellas en las fuentes abordadas, se vieron ante la necesidad de hacer uso de los medios que la beneficencia puso a su alcance, no lo hicieron desde una pasividad que se revele en la mera utilización de tales recursos, sino desde un lugar que subraya su sentido de la necesidad, al tiempo de que se mostraron conscientes también de sus derechos. Ser trabajadores, viudos, viudas, enfermas, los hizo entablar unas demandas movilizando estrategias desde las mismas presentaciones o recurriendo a terceros para que los ayudaran a interpelar a las benefactoras locales, a fin de conseguir su objetivo, que a veces no era más que disponer de un espacio para sus hijas solo por un tiempo, como lo muestran los pedidos de restitución de niñas.

\footnotetext{
41 ASCJA, Actas, 21-1-1900.

42 En otras ocasiones se recibieron niñas que no tenían la edad requerida, como las dos hermanas huérfanas de 2 y 6 años que en 1903 fueron aceptadas. ASCJA, Actas, 4-12-1903.
} 


\section{Familias pobres, niñas y benefactoras}

En síntesis, este trabajo ha buscado brindar una aproximación tomando cierta distancia de las interpretaciones más tradicionales que han visto en los asilos espacios de control y disciplinamiento de comportamientos sociales. Así, se puso el acento en mostrar cómo detrás de los pedidos a las instituciones asilares, se revelan las estrategias de los sujetos que recurrieron a ellas, entablando unas relaciones basadas no sólo en sus necesidades, sino también en sus propias expectativas y nociones de derechos. 